\title{
Learning English in the shadows: Understanding Chinese learners' experiences of private tutoring
}

\section{ABSTRACT}

Since private tutoring has received increasing attention in research as a global educational phenomenon with significant implications for educational practices, it has become necessary for TESOL researchers and practitioners to become aware of its impact on language learning and pedagogy. This study investigated the learning experience and reflections of 14 Chinese learners who had received English private tutoring (EPT) during their secondary education in Hong Kong. Each participant completed a background questionnaire and participated in a one-to-one semi-structured interview. The analysis revealed participants' ambivalent and paradoxical attitudes toward EPT. While they considered EPT indispensable for secondary education, they did not regard it as an effective way to increase their English proficiency because of its excessive focus on examination skills instead of the use of English as a language of global communication. The findings were interpreted with references to contextual conditions where learning for assessment and competitions prevail. This study sheds light on the world of "shadow education" that exists beyond the boundaries of mainstream classroom settings. Further research on "shadow" TESOL practices is needed to help researchers and practitioners in TESOL to appreciate the unintended consequences of educational changes and their profound impact on learning as mediated by sociocultural conditions.

\section{INTRODUCTION}

Private tutoring emerged to be one of the most significant education issues gaining increasing attention from researchers and policymakers worldwide because of 
its "far-reaching implications for the nurturing of new generations, for economic and social development, and for the operation of school systems” (Bray \& Kwo, 2014, p. viii; also Bray, 2009). Defined as fee-paying teaching of academic subjects outside school hours, private tutoring is a form of "shadow education," whose content mimics and is parallel to mainstream education (Bray, 2009, p. 11). Driven by the hope that investments in private tutoring may help children achieve educational successes and social mobility, enthusiastic parents have made private tutoring a major industry across the globe (Buchmann, Condron, \& Roscigno, 2010; Bray \& Kwo, 2014; Bray \& Lykins, 2012; Bray, Mazawi, \& Sultana, 2013; Dawson, 2010; Forsey, 2013). In many contexts, English language is one of the major subjects offered by tutorial institutes and an increasing number of learners participate in English private tutoring (EPT) as one of the most important out-of-class learning activities, with the intention to improve their English results in mainstream education and high-stakes examinations. However, little is known about these learners' experiences and reflections. Since EPT significantly impacts student experiences, attitudes and motivations in English learning (Hamid, Sussex, \& Khan, 2009), it has become necessary for TESOL researchers and practitioners to have a better understanding of language learners' participation in EPT. Without considering these experiences, teachers, researchers and policymakers “would only see a partial picture of [students'] real English-learning experiences and proficiency" (Lee, 2010, p. 70) and miss "alternative perspectives on the meaning of, and social and cognitive processes involved in, language learning and teaching” (Benson \& Reinders, 2011, p. 1).

To this end, the current study draws on the reflections of 14 Chinese learners on their English learning experiences in shadow education during their secondary school education in Hong Kong. In the coming sections, I will first review relevant studies on EPT and contextualize its discussion with sociocultural conditions in Hong Kong 
since understanding of these learners' experiences will depend on “developing knowledge of the sociocultural contexts in which that language occurs and for action in which it exists” (Atkinson, 1999, p. 647; also Gao, 2008; Yang \& Kim, 2011). Then, I will describe the research methods used in the study to gather data about participants' EPT experiences before I present how the participants reported and reflected on their experiences.

\section{LITERATURE ON ENGLISH PRIVATE TUTORING}

As observed by Hamid et al. (2009, p. 283), EPT is “of substantial interest to TESOL, applied linguistics, and language education,” but their study remains one of the few focusing exclusively on this issue in TESOL contexts. Hamid et al. (2009) investigated student attitudes and motivations in EPT in Bangladesh and related them to the school system, parent and student expectations, and outcomes of learning. A questionnaire was administered to 228 tenth-grade students, 14 of whom were selected for one-to-one interviews. The study showed that students saw EPT as imperative for successful learning because of what they perceived as the poor teaching in mainstream education. Another recent study by Lee (2010) reported on the results of a survey of 43 university freshmen in Korea about their pre-university exposure to out-of-school English learning programs and explored the cases of seven students among the sample. Lee found that the students who had participated in out-of-school English learning programs, including EPT, had significantly higher English proficiency than those who only relied on mainstream education.

While the studies by Hamid et al. (2009) and Lee (2010) have made important contributions to TESOL, they paid less attention to learners' critical reflections on their EPT experiences and its effectiveness. This dimension is crucial because the “consumer” views of students about "what does and does not work for them are useful 
for improving teaching effectiveness” (Ma, 2012, p. 281). Like many studies of shadow education, Hamid et al. (2009) recruited secondary school students for their study, but their reflections might be limited because they had not yet completed secondary education. Although Lee (2010) studied the experience of post-secondary school students, he acknowledged that his study was "rather exploratory” (p. 72) since he focused on participants' English-educational background instead of their views toward EPT based on their reflections. Moreover, these studies in some way correlated the effectiveness of EPT with learners' English test scores, but this did not necessarily mean that EPT helped learners to master the language for daily communication. Hamid et al. (2009) also acknowledged that it was not clear whether the improvement in scores could be attributed to EPT, because EPT and mainstream education take place at the same time.

Looking across the research in this area, Zhan, Bray, Wang, Lykins, and Kwo (2013) describe the literature linking tutoring and academic achievement as "not robust" and suggest the evaluative criteria for "effectiveness" should "fit the motivations of the consumers" (p. 2). Therefore, learners' voices are essential in evaluating the effectiveness of EPT through reflections on their experiences in this form of shadow education.

Based on the experiences of learners who have finished their secondary education, the current study investigated the extent to which EPT is perceived to be effective in helping secondary school students to learn English. To achieve this objective, the following research questions were addressed:

1. What experiences do learners in EPT have in secondary education?

2. Reflecting on their EPT experiences, how do learners perceive the effectiveness of EPT?

Because of the significant role of sociocultural contexts in understanding 
learners’ language learning experiences, the following section describes the English learning context and the current state of EPT in Hong Kong.

\section{THE CONTEXT}

There has been a long tradition of valuing education in Hong Kong. In line with the cultural tradition, teachers are well-respected as authority and learners are noted for their willingness to invest time and effort in improving their academic results (Carless, 2011; Kwok, 2004). In ancient China, success in the imperial examination opened the door for examination candidates to a career as a government official, and the legacy of the imperial examination system may have caused today's emphasis on achievement in high-stakes examinations (Carless, 2011; Kwok, 2004; Watkins, 2009). Efforts have been regarded as the key to academic success, which is closely associated with upward social mobility (Bray \& Lykins, 2012; Carless, 2011; Gao, 2008). This has led to intense academic competition (Watkins, 2009).

Competition is even fiercer among English language learners in Hong Kong. Since the end of British colonialism in 1997, Hong Kong has adopted a language policy of "biliteracy" (Chinese and English) and "trilingualism" (Cantonese, Putonghua and English). English is learned as L2 and is a compulsory subject in the curriculum. It is also used as the medium of instruction (MOI) in many secondary schools, especially the elite ones. ${ }^{1}$ Described as "the language of global communication” (Curriculum Development Council (CDC) \& the Hong Kong Examinations and Assessment Authority (HKEAA), 2007, p. 2), English plays a prominent role in Hong Kong, particularly in government and business sectors. As

\footnotetext{
1 The government's Education Department announced in 1997 that students' "mother tongue” (Cantonese) should be used as the medium of instruction (MOI) in a secondary school unless the school could demonstrate that its teachers and students were competent to teach and learn in English. However, the policy was "fine-tuned" in 2009 to allow schools flexibility to choose their MOI because of the continuous outcry and protests from schools, parents and students supporting the use of English (Education Bureau, 2009).
} 
Nunan (2003) describes, "English symbolizes wealth and power in Hong Kong” (p. 597). It is not only a core subject students need to pass in public examinations to compete for the limited university places, but also "a crucial asset in deciding how far they can move upward” (Gao, 2008, p. 172).

As a result, Chinese parents tend to be willing to invest in education to secure their children's competitive edge for the pursuit of social mobility, and this has led to the popularity of private tutoring (Bray \& Lykins, 2012). Zhan et al. (2013) surveyed 1,624 Hong Kong secondary school students and found that $61.1 \%$ had utilized some form of private tutoring services in the past 12 months, including one-to-one tutoring, small-group tutoring, lecture-type tutoring, and online tutoring. English was the most popular subject among others in tutoring because $65.2 \%$ of the respondents reported that they had used tutoring services in English. With their parents' investment in private tutoring, students are generally willing to spend extra time and effort learning out-of-class in hopes of greater returns in the future through winning the academic competition.

\section{METHODOLOGY}

The study was informed by a recent paradigm shift in language learning and teaching research to a more qualitative, contextualized approach, which challenges its over-reliance on the survey method and decontextualized pictures of learners' experiences and beliefs (Dörnyei \& Ushioda, 2011; Gao, 2008; Yang \& Kim, 2011). It has been suggested that contexts have a strong impact on learners' beliefs, influencing their behaviors and learning experiences, which are shaped by their learning process, motivations and attitudes toward various teaching and learning approaches. Taking sociocultural contexts into consideration, this study explored learners' EPT experiences and their reflections on such experiences through narrative inquiry. 
Narrative inquiry is a process of telling, analyzing and criticizing personal stories through a variety of instruments such as interviews (Barkhuizen, Benson, \& Chik, 2014; Clandinin \& Connelly, 2000). As Clandinin and Connelly (2000) state, “[e]xperience happens narratively. Narrative inquiry is a form of narrative experience. Therefore, educational experience should be studied narratively” (pp. 18-19). The use of narrative inquiry in TESOL has been emphasized by Bell (2011), who states that narrative allows researchers and teachers "to reach a richer understanding of the teaching and learning process" (p. 580), and "narrative inquiry has a great deal to offer the field of TESOL” (p. 583). Therefore, narrative inquiry through the instrument of one-to-one semi-structured interviews was adopted in this study to elicit and reflect on learners' experiences in EPT. An initial background questionnaire ${ }^{2}$ was used to recruit participants who had grown up and received secondary education in Hong Kong and had experience participating in EPT, as described below.

\section{Participants}

For convenient sampling, all the local $^{3}$ Year One undergraduates (75 in total) studying at a university in Hong Kong and living in a hall where I served as a resident tutor were invited to participate in a questionnaire study. The participants were asked in the questionnaire to provide their biographical information; detail their previous EPT experience(s), including the type(s) of tutoring and period(s) of participation; and consent to take part in the one-to-one in-depth interview. First year undergraduates were chosen for this study because they were expected to have fresh memories of their English learning experience and were able to recount the whole period of secondary school life and evaluate the effectiveness of EPT. All participants were recruited on a voluntary basis.

\footnotetext{
2 See Appendix A.

3 “Local” means having a home in Hong Kong when they applied for a place of residence in the hall.
} 
Twenty-one undergraduates returned their questionnaire and consented to participate in the study. However, three of them had completed their secondary education overseas, so they had no experience in the local secondary curriculum; two did not receive EPT; and two withdrew. Therefore, the remaining 14 respondents were selected to take part in the interview; they had all studied in the local curriculum and had participated in some form of EPT. They had all grown up in Hong Kong and had studied English for about 16 years under the Hong Kong education system before being admitted to university. ${ }^{4}$ They were all bilingual (Cantonese and English) Year One undergraduates with different academic majors.

\section{Data collection}

A pilot study had been carried out prior to the main study. A Year Two undergraduate living in the same hall as the participants in the main study was invited to complete and comment on the draft questionnaire and participate in the pilot interview. Questions in the questionnaire were subsequently modified, and some interview questions were re-worded and rearranged.

The interviews ${ }^{5}$ were semi-structured and conducted in a one-to-one, face-to-face format. The one-to-one format allowed the study to focus on the individual experiences of the learners rather than commonalities in larger groups. With face-to-face interviews, participants' reactions could be observed, such as when they were enthusiastic about a particular point in the discussion (Savin-Baden, Gourlay, \& Tombs, 2010). Each interview started with structured questions related to the number of instances they participated in EPT and the types, frequency, duration

\footnotetext{
${ }^{4}$ The 16 years include 3 years of kindergarten, 6 years of primary schooling, and 7 years of secondary schooling. They all went through two public examinations: the Hong Kong Certificate of Education Examination (HKCEE), which students took after they had finished Form 5, and the Hong Kong Advanced Level Examination (HKALE), which they took after they had finished Form 7.

${ }^{5}$ For the interview probes, see Appendix B.
} 
and costs of each instance, which also validated their questionnaire responses. More open-ended questions were then asked, including their reasons for participation, learning process, beliefs and attitudes toward EPT, and how they perceived their learning outcomes. Each interview lasted for 30 to 60 minutes, depending on the number of instances of EPT experiences the interviewee had. To achieve in-depth understanding of their experiences, I probed for relevant information by sharing and comparing with them my experiences as a tutee when I was a student, and as a tutor when I taught in tutorial schools. I did that after they had narrated their experience to avoid biasing their views. This increased the "wakefulness" of the researcher, being conscious about critical issues that might impact the study (Clandinin \& Connelly, 2000). Having lived in the same hall as a resident tutor with the participants for eight months, I had developed a trusting relationship with them, which allowed them to be freely and fully involved in the conversations and give more in-depth and trustworthy responses (Bell, 2011). The interviews were audio-recorded. All the data was transcribed into Chinese verbatim and translated into English for analysis. ${ }^{6}$ Regular attempts were made to meet the participants for short conversations when more information about their EPT experiences was needed.

\section{Data analysis}

The questionnaire data offered an overview of the EPT experiences each participant had and the basis for analyzing the in-depth interview data. The qualitative data was coded, which then led to identifying themes emerging from the interviews and constructing arguments to answer the study’s research questions (Holliday, 2010).

\footnotetext{
${ }^{6}$ The interviews were conducted in Cantonese, the interviewer's and interviewees' first language (L1), in order to elicit the most accurate and rich data possible. Every effort was made to keep the English translation as close to Cantonese as possible. Half of the transcripts were checked by two bilingual (Chinese and English) colleagues who are experienced researchers in Applied Linguistics to ensure the quality of the translation.
} 
First, the interview data for each participant was sorted chronologically from the first EPT experience to the last, which shaped the plots of their narratives, followed by their reflections. The transcripts were read, and key words were identified. These key words were recorded and sorted into thematic nodes, such as their learning process, teaching and learning approaches, attitudes, motivations and perceived effectiveness. Then the participants' experiences and reflections were compared and contrasted according to these themes. Excerpts pertaining to these themes were identified. The transcripts were revisited multiple times to reassess the data and refine or change the themes. To strengthen the collaborative feature of narrative research, the learners' narratives were co-constructed through face-to-face and online conversations after the interviews (Clandinin \& Connelly, 2000) and the quality of the narratives was ensured through member checking. A research diary was kept throughout the whole process to maintain "an ongoing dialogue between collecting data, writing and analysis" (Holliday, 2010, p. 102). Furthermore, coding of one-third of the transcripts and all the selected excerpts was checked by two experienced researchers in Applied Linguistics to enhance the analysis.

Having the same cultural and educational background with all the interviewees and understanding the general state of EPT in Hong Kong, I could interpret the participants' experiences more accurately and minimize any cross-cultural misinterpretation (Bell, 2011; Clandinin \& Connelly, 2000). Moreover, adopting Breen's (2007) theory on negotiating the insider-outsider dichotomy, I can be considered to be in a continuum between an insider of EPT as a former tutor and an outsider as a current researcher. As an insider, who had engaged in full-time tutoring for several years, I had enough knowledge about the context of EPT to understand the situation of teaching and learning within. As an outsider, who had left the tutoring industry, the data could be analysed and interpreted with a reasonably objective lens, 
generating a more complete picture of learners’ EPT experiences.

\section{FINDINGS}

This section is divided into two parts to address the two research questions learners' accounts of their EPT experiences and their reflections on those experiences. The study found that all the 14 participants enrolled in EPT during senior secondary school (Form 4-7). Only two of them (Brad and Chris) enrolled during junior secondary school (Form 1-3), and their experiences were similar to those who enrolled during senior secondary school. Therefore, to limit the scope for more effective comparisons, the findings are presented and discussed with reference to their EPT experiences during senior secondary school. The types, frequency, duration and costs of the EPT they had received in that period are summarized in Table 1.

Table 1 Types, frequency, duration and costs of EPT participants received in senior secondary education (Form 4-7)

\begin{tabular}{|c|c|c|c|c|c|}
\hline Types & $\begin{array}{c}\text { No. of } \\
\text { participants }\end{array}$ & $\begin{array}{c}\text { Participants } \\
\text { (Pseudonyms) }\end{array}$ & $\begin{array}{l}\text { Frequency } \\
\text { per week }\end{array}$ & $\begin{array}{c}\text { Duration per } \\
\text { lesson (hours)* }\end{array}$ & $\begin{array}{l}\text { Monthly costs } \\
\text { (HK \$)* }\end{array}$ \\
\hline one-to-one & 0 & - & - & - & - \\
\hline small-group & 1 & Brad & 2 & 1 & 1600 \\
\hline \multirow{13}{*}{ lecture-type } & \multirow{13}{*}{13} & Chris & 1 & 1.5 & $200-500$ \\
\hline & & Tai & 1 & $1.25-6$ & $400-500$ \\
\hline & & Joan & 1 & $1.5-2$ & $800-900$ \\
\hline & & Lam & 1 & 1.5 & 450 \\
\hline & & Yan & 1 & 1.25 & $180-400$ \\
\hline & & Evan & 1 & $1.25-5$ & $200-700$ \\
\hline & & Alan & 1 & 1.25 & 400 \\
\hline & & Wayne & 1 & 1.5 & $550-580$ \\
\hline & & Fiona & 1 & 1.5 & $400-500$ \\
\hline & & Ray & 1 & 1.25 & 400 \\
\hline & & Hanson & 1 & 1.5 & 500 \\
\hline & & Ian & 1 & 1.5 & 400 \\
\hline & & Sung & 1 & 1 & 500 \\
\hline
\end{tabular}




\begin{tabular}{|c|l|l|l|l|l|}
\hline online & 0 & - & - & - & - \\
\hline
\end{tabular}

* Duration per lesson and monthly costs are shown in a range because the participants may have more than one EPT experience

What these background figures indicate is that lecture-type tutoring is most popular among senior secondary school students. Each session is around 1 hour and 15 minutes, once a week, although some tutorial centers allow tutees to stay and work on examination papers for several hours (e.g. Tai and Evan). The monthly tuition fee varies because of occasional discount and the scale of the tutorial center (e.g. Joan and Evan received EPT in a small-scale tutorial center, which generally provides more attention to the tutees than large-scale tutorial centers do, thus charging more), but it is typically around HKD $\$ 500$ for four sessions, which is more affordable than other types of tutoring. ${ }^{7}$

\section{Learning experiences in EPT}

In this section we learn what the participants reported about the nature of their experiences in the EPT courses, that is, what and how they were taught. The narratives derived from the interview data show the learners' various EPT experiences, consisting of their learning process, motivations, and their preferred teaching and learning approaches.

Among the interviewees, Brad had a rather atypical EPT experience. He was the only one participating in small-group tutoring and tutored by a native English speaker in TESOL (NEST). He believed that a NEST could provide a monolingual environment for him to have more exposure to conversational English. At the

\footnotetext{
${ }^{7}$ As mentioned by the interviewees and from my insights as an ex-tutor, tutees generally expect quick, direct examination tips instead of focusing on global communication competence. Interaction is minimal because tutors need to keep the lesson going smoothly. The class size is usually large, with a maximum of 45 students per classroom as regulated by the Fire Ordinance (Bray \& Kwo, 2014), although some classrooms are connected with a piece of glass as a wall in between.
} 
beginning, he, together with a classmate, learned English through playing card games with the NEST in a "natural" and "relaxing" manner. He appreciated the communicative approach adopted so that he could train himself to listen to and speak English spontaneously. However, because the public examination was approaching, they asked the tutor to train them specifically for the oral examination. They then learned English through practicing past oral examination questions, which Brad felt less interesting but more "useful.” Brad commented that he was still motivated simply because of the fact that the tutor was a NEST, as he, like many secondary school students in Hong Kong, seldom had opportunities to interact with NESTs outside school. Therefore, the tutor could cater to his learning needs.

Brad was the only one among the 14 participants who was tutored by a NEST and had never participated in lecture-type tutoring. The other 13 had all chosen the mass-lecturing format which adopted a top-down, transmission-oriented instructional approach and were all tutored by non-native English speakers in TESOL (NNESTs). They learned by cramming with short-cut and examination skills, and analyzed past examination papers and looked for trends and patterns in them:

[The tutor] told you what the main point was, so as to keep that word in mind, as the Examination Authority always used that word, and when you saw a certain word, it was very probably incorrect. (Chris)

The examination-oriented approach adopted by tutors was mentioned by all the interviewees. They were usually provided with mock papers, model essays, and ready-to-read notes, which were then discussed by tutors. They were satisfied with the passive learning approach by simply listening to the tutors and copying what the tutors wrote as shown on the screen. Every lesson, they were fully crammed with content so that they felt the lesson was worth the time and money they had paid. Yan 
stated:

[The tutor] told me a lot of things non-stop, kept feeding us a lot of things, speaking so fast that he could talk about writing and do listening and other exercises, very rich in content... In such a lesson... I felt that I had already learned more than what I had learned at school for half a year or one year. (Yan)

Yan, like other interviewees, preferred being spoon-fed a large amount of material in a short period of time. The learning process mainly involved memorizing patterns and useful phrases for use on the public examination as well as drilling grammar exercise and past examination questions.

The data also demonstrated that the interviewees were motivated differently, depending on what their tutors did. They could be motivated when they saw role models. For example, Ian was attracted by the tutor’s professional image:

I felt that [the tutor] was so great. ... Following him, I would be able to learn a lot. ...

I wanted to be as great as him. (Ian)

Other learners described viewing their peers as role models when they saw the tutors praising their well-written essays. These high-performing students motivated them to study harder because they "envied them and wanted to be like them" (Yan), although some might feel stressed when they realized their standard was lower than their peers', whom they regarded as "competitors".

Besides role models, the interviewees were motivated by the positive learning environment of the tutorial classrooms. For example, Lam indicated that the use of Cantonese as the MOI helped him concentrate. He explained that when English was used all the time at school, he could not understand everything and would lose focus. Moreover, listening to jokes in their L1, learners would have more fun, which made 
them more relaxed and motivated:

[The tutor] created a very good atmosphere, like he had some pet phrases, which were funny but wouldn’t make you lose track. And he always made jokes... It was fun to have his lessons, so I felt he gave me great motivation. (Chris)

More than half of the interviewees mentioned that they felt motivated by tutors' sense of humor, because jokes created an enjoyable and relaxing learning environment for them, thus increasing their interest in learning, though Fiona and Wayne commented that sometimes they were demotivated when the tutors wasted too much time joking.

A motivational atmosphere could also be created by the tutors' passion. Joan participated in lecture-type tutoring in a small-scale tutorial center, and she developed a good relationship with her tutor. She described her tutor as "very friendly" and "passionate" that she would worry about the students who did not perform well academically. Fiona did not have such a close relationship with the tutor because her tutor was a "star," but she could also feel the tutor's passion:

[The tutor] seemed to have a passion to ask us to feel that English was really important and ask us to do better on the exam... So he made me have high motivation to do better in exam. (Fiona)

While the interviewees mentioned a variety of motivating factors, they all indicated that the main motivator was the public examinations, because they all had a clear goal - to get good results and secure a place at university. Therefore, tutors always emphasized the importance of examination preparation, which became the key motivator for the participants.

The narratives of participants' EPT experiences revealed that they generally found the sessions motivating, though for different reasons, and not for improving 
their English as a communicative tool, but rather for instrumental purposes. They were comfortable playing a passive role during the lessons and accepted the cramming style of EPT. These findings formed a solid base for them to reflect on and critically evaluate the effectiveness of EPT.

\section{Reflections on EPT}

After narrating their experiences, the interviewees were asked to reflect on them and evaluate the effectiveness of EPT. They were also asked whether they thought other secondary school students should enroll in EPT. The purpose of these reflections was to provide a richer context for understanding what the participants had reported about the nature of their EPT experiences.

Interestingly, while most of them found EPT beneficial at the time of secondary schooling, all but one stated that, in looking back on those experiences as university students, it did not effectively improve their English proficiency but rather only their examination skills. As Alan commented:

[EPT] would not make you learn English... Actually it [just teaches you] how to do better on English exams. (Alan, Emphasis added)

Alan added that although some tutors claimed they taught "real English,” he believed it was just a gimmick, because a majority of students receiving EPT only aimed to perform well on public examinations. He added, “for learning English, tutoring didn’t help much.” Hanson echoed this belief:

You can learn exam skills very quickly [in EPT], but it doesn't mean that your English proficiency is really higher. (Hanson)

He mentioned that even if students received good results on public examinations, it 
could be misleading because they might only know how to score well. He further explained that in EPT, students memorized a lot of vocabulary items and sentence structures, but they might not remember them after they finished the examination. This view was also shared by Yan and Fiona. Yan reflected on her own experience and said:

Now I think, although [the tutors] taught very well, there are many things that I cannot remember. You don't remember if you do not review them. That means your target was simply the exam, and you recited, recited and recited, until the exam finished, and you didn't keep reciting or reviewing. But if you really learn it in everyday life, maybe you can remember things more easily. That means when you learn exam skills, you are learning in a very rigid mode, a model for you to follow... The tutor may have read a lot of past papers, analyzed a lot, and then he concludes with a fixed format and asks you to follow. This becomes following his way of thinking. The tutor may be very great, having thought about a lot of things, but it is not you who have thought about a lot of things. (Yan)

Brad and Lam also mentioned that what they learned in EPT was too rigid to be used in daily life. Lam shared this reflection on his university experience to contrast it with his EPT experience:

I got to know some foreigners in university, and I am not used to talking to them. Maybe the words they are using are not what we have been learning. For example, [in EPT] we learned... like, writing business letters..., but I wouldn't use these while talking to them, and it was difficult at the beginning to communicate with them. ... They told me that, while talking to them I used formal English, too formal, and they thought I was not using spoken English. (Lam) 
Brad added that he encountered a lot of people who were trained well for examinations but could not use English appropriately in various contexts. He believed that EPT could "only increase the fundamental awareness of the language but not enhance the sense [of using the language].”

Joan was the only one who strongly believed that EPT was useful in any way and believed "tutoring [was] the best way to learn English" because "it was useful for the exam and also for [one's] life.” This could be attributed to her negative English learning experience at school, as she commented that most schools, including hers, could not teach English well. Therefore, she strongly recommended EPT. Five other interviewees (Lam, Hanson, Evan, Ray and Sung) did not have such an extreme view, but still thought secondary school students should enroll in EPT. Like Joan, Evan recommended EPT, saying that it had been taken for granted that Hong Kong students should participate in tutoring, because schools could not focus on teaching examination skills. He reasoned it was a waste of time to go to school. Nevertheless, contrary to Joan and Evan, Ray thought that "participating in tutoring does not mean it is the mistake of schoolteachers.” He continued:

Sometimes your schoolteacher teaches well, but after learning [at school], the students just want to reinforce what they have learned, so they go to tutorial class. ... During the levels when you need to have exams, it is impossible not to teach students exam skills. You won’t say “you have to be interested in English”. Because the world is realistic, if you don’t have good results, you cannot climb up the academic ladder. (Ray)

Ray's comment also raised the point that in order to be pragmatic, secondary school students should learn for assessment and not for interest. Such an idea was reinforced in EPT, as Hanson mentioned: 
I heard from the tutor that, "the period of [A-level exam] is not for you to pursue knowledge; you pursue knowledge in university.” So when I was preparing to take the A-level exam I felt that doing well in the exam was most important. I shouldn’t care about anything else. (Hanson)

The tutor's comment promoted the importance of examinations in secondary education, and he was there to cater to students' need to score well. Many interviewees, like Sung, shared the view that learning examination skills in EPT is necessary for scoring well and hence getting into university:

Many people say that [EPT] only teaches you exam skills and you actually do not learn anything useful, but I think, under the Hong Kong education system, passing the exam is very important. I mean if it really helps you, it is not a problem to receive tutoring.... I think it is better than nothing. (Sung, Emphasis added)

Interestingly, however, Sung indicated that he did not actually know how much EPT helped him, because he was not sure whether he would have received the same score without it.

While six interviewees recommended EPT to other secondary school students, the rest said it depended on what kind of students they were and what they wanted. Alan, Fiona and Brad believed that if the students had initiative and a good English foundation, they would not need EPT, because they should be able to learn independently. However, Chris thought that it would be a waste of time to join EPT if the students' English standard was not high enough, because they would not be able to follow the lessons, which were packed with content. Yan, Ian and Tai suggested that EPT would be useful only for those interested in improving their examination skills but not their overall English proficiency. As Tai stated: 
I would recommend you seek help from schoolteachers if you think you want to focus on your English foundation, as they can really help. But if you want to get a good score, I would recommend you seek help from tutors. (Tai)

Wayne expressed a more negative view about EPT and said that if he could choose again, he might not have participated in it. He went on to explain:

[The tutor] just keeps printing handouts for you to do, but you can get these things like past papers on the Internet. It is not essential, but if you are really lazy, like I was, you may go for tutoring, letting him push you. But if you have the persistence, I don’t think it is necessary. (Wayne)

Wayne added that although he learned examination skills through EPT, when it came to the real examination, he could not apply them, because he realized that examination papers could vary in many different ways. When a question changed a bit, the skills became inapplicable.

Summarizing the findings in this section, it appears that, as university students, the participants had somewhat ambivalent reflections on their EPT experiences. They tended to believe that EPT helped to develop their examination skills; they also felt it was not effective in increasing their English proficiency for daily communication or cultivating an interest in the language. However, in an education system based on public examinations, they resorted to taking "short-cuts" (Tai) - quick fixes but unhelpful in the long run. In other words, they appeared to accept the examination-oriented nature of the EPT lessons, thus adopting a fundamentally pragmatic attitude toward EPT as opposed to expecting EPT to promote genuine communicative competence in English. In the final analysis, and taking into account what they had since learned as university students, they generally believed that secondary school students should engage in the shadow world of EPT. 


\section{DISCUSSION}

Looking broadly across its findings, this study suggests that the participants had a complex and seemingly contradictory attitude toward EPT, especially when looking through the lens of the mediating effects of context on learner attitudes and behaviors. On the one hand, they appreciated the ways in which EPT helped prepare them for the all-important examinations they faced. On the other hand, they lamented the apparent inability of EPT to prepare them for authentic interaction and communication in English. This complicated set of responses to EPT is one of the study's contributions to the literature in the area of shadow education.

With respect to the study's first research question about what EPT experiences the learners had, it was found that they tended to depend on tutors to spoon-feed them examination skills in a short period of time. They were highly instrumentally motivated, as evidenced by their pragmatic goal of performing well in public examinations and securing a place at university, although some might also be motivated by role models and the positive learning environment they experienced in EPT. This finding is consistent with other studies on shadow education in Hong Kong (e.g. Kwok, 2004; Zhan et al., 2013). However, regarding the second research question about the participants' reflections on their EPT experiences, it was discovered that the interviewees tended to distinguish between two aspects of effectiveness, scoring and proficiency, with the former emphasizing performance in examinations and the latter focusing on the use of English for genuine communication. This finding was different from previous studies of EPT, which usually related proficiency to examination results (Hamid et al., 2009; Lee, 2010). Moreover, contrary to the findings from Hamid et al. (2009) that "not a single interviewee was critical of [EPT]” (p. 302), almost all the interviewees in the current study expressed 
some criticisms of EPT for its excessive focus on examination skills, which they felt were not useful for everyday communication. This was probably because they had already finished their secondary education and could reflect on their own experiences through a more critical and objective lens as university students. The change of sociocultural context, as Yang and Kim (2011) suggest, may have influenced learners’ beliefs in relation to L2 learning. That is, no longer under the pressure of public examinations, they could consider the use of English in a wider context, such as their university life.

Overall, drawing on the findings from the two research questions, the study shows that EPT may not be effective in helping secondary school students to increase their overall English proficiency for genuine communication, or at least is not perceived to be effective in this respect. However, it should also be noted that developing communicative competence in English is not a stated goal of typical EPT courses in Hong Kong. They are foregrounded as “cram courses” aimed at developing examination competence rather than actual communicative proficiency in the target language. In this regard, it is interesting that, as university students, the participants were still critical of EPT, despite knowing what the primary aim of EPT tends to be.

If what the participants' asserted is accurate, one of the reasons that EPT may undermine effective English learning is its over-emphasis on examinations at the expense of developing communicative skills. Ironically, the interviewees still considered developing examination skills in EPT indispensable for tackling public examinations, as they could not acquire such skills from mainstream education. Because of the ideals of education, schoolteachers are supposed to train well-rounded students and cannot overtly "teach to the test." This is where EPT fills a gap, as the participants acknowledged. This is one of the study's most interesting findings, in that the participants upheld the importance of achieving communicative competence 
through EPT but at the same time accepted the fact that EPT was better equipped to address examination-oriented needs. They were comfortable with this seemingly contradictory view of EPT.

However, unlike studies elsewhere showing students’ perception of poor English teaching at school as a main reason for receiving EPT (e.g. Hamid et al., 2009), learners in this study did not necessarily feel that schoolteachers taught poorly. They understood and accepted the realities faced by mainstream teachers. Because of the examination-oriented education system, which is deep-rooted in many Asian settings like Hong Kong and mainland China (Carless, 2011; Watkins, 2009) and is increasingly prevalent worldwide (Clarke \& Morgan, 2011; Frick, 2013), they were willing to sacrifice their free time to study for examinations, in hopes of a better chance to pursue higher education (Bray \& Lykins, 2012; Carless, 2011; Kwok, 2004). They sought help from EPT to learn examination skills, which the mainstream schooling could not fully account for. In this regard, they saw EPT as performing a valuable function relative to the perceived shortcomings of mainstream education.

Approaches to teaching and learning English may be confined by contextual realities. For instance, even though one of the participants (Brad) enjoyed learning English through playing games with his tutor, he had to focus on practicing examination questions in the end. Ideally, English should be learned and used as a language of global communication (CDC \& HKEAA, 2007), but in reality, learners may resort to focusing on examination techniques and ignoring the use of English in authentic contexts for pragmatic reasons that override other interests or preferences they may have. Thus, a valuable contribution of this study is that it sheds light on the positive role(s) that EPT ultimately plays in places like Hong Kong, where the mainstream educational system pursues one set of goals (development of communicative ability), but success is achieved by pursuing others (i.e., examination 
competence).

Another reason the participants considered English learning ineffective in EPT, at least with respect to developing proficiency in English, is what they saw as its superficial and teacher-dependent teaching and learning approaches. Even though some learners believed they were learning something useful at the time they received EPT, they did not necessarily maintain that sentiment after they had finished their secondary education. The skills learned through analyzing patterns and trends in past papers in EPT may be too formulaic to be flexibly applicable to the actual examinations, let alone natural contexts. This became particularly evident when the interviewees needed to use English to communicate with other students and professors as university students. Moreover, when the interviewees reflected on their experiences, they indicated they had already forgotten many phrases and sentence structures acquired during EPT. This can be attributed to the teacher-centered approach in EPT, which echoes the long dominant culture of teacher authority in Chinese contexts. Passive learning is reinforced, and learners lacked opportunities for experiential learning, thus relying on receptive knowledge and memorization, resulting in surface rather than deep learning (Carless, 2011). Such instructional approaches adopted in EPT run contrary to the goal of student-centered and autonomous language learning (CDC \& HKEAA, 2007; Miliander \& Trebbi, 2011). However, it must also be remembered that, for the most part, the participants in this study accepted their passive roles and the emphasis on cramming. They may not have liked it, but few complained about it. This finding once again reveals the ambiguous nature of the participants' experiences with and feelings about EPT and thus the nature of EPT itself.

A surprising finding in the study was that the use of Cantonese as the MOI was acknowledged as a strength of EPT over mainstream education, and NNESTs were 
much more popular than NESTs as tutors. In Hong Kong, while "fine-tuned" language policy has been introduced to cater to the needs of the general public pressing for the use of English as the MOI at school (Education Bureau, 2009), this may not be an advantage in EPT. In this study, only one interviewee (Brad) mentioned the experience of being tutored by a NEST using English as the MOI. All other interviewees were tutored in their L1 by native Cantonese speakers, and many expressed appreciation for this. This finding aligns with the preference for teachers' use of students' L1 in Ma’s (2012) study as the most prominent merit of local English teachers among secondary school students in Hong Kong. From the students' perspective, it facilitated communication in the classroom, particularly for explaining the meaning of difficult vocabulary and grammar items. In addition, the popularity of NNESTs over NESTs as tutors might also be attributed to NNESTs' better understanding of the sociocultural and socio-historical contexts, which facilitates their teaching and pedagogical choices relevant to the local settings (Mahboob, 2010). This is particularly evident when learners expect their tutors to understand the local examination system and teach them examination skills rather than English for communicative purposes. Moreover, as mentioned by the interviewees in this study, use of their L1 permitted them to understand the tutor's jokes more easily, because the comprehension of humor requires sociocultural knowledge and can be challenging for NESTs in an L2 context (Ma, 2012; Mahboob, 2010; Wulf, 2010).

\section{CONCLUSION AND IMPLICATIONS}

This paper investigated Chinese learners' reflections on English learning experiences in private tutoring with references to contextual conditions and the growing emphasis on achievements worldwide. The data revealed that EPT pedagogy tended to be teacher-centered, with excessive focus on examination techniques and 
negligence of the use of English in authentic communication contexts. Based on the findings for the two research questions, it can be concluded that although EPT may appear to be sought after by many secondary school students in examination-oriented contexts like Hong Kong, there is no evidence in acquisition of overall English proficiency for genuine communication. An important caveat here is that developing such proficiency is not necessarily a common goal in EPT courses, thus complicating the picture of how to generate effective evaluations of such courses. Should the significance of EPT courses be judged according to how well they do what they claim to do, or by what should have been achieved?

The study provides insights for policymakers and TESOL practitioners not only in deep-rooted examination-oriented Asian settings like Hong Kong, Japan, Korea and mainland China (Bray \& Lykins, 2012; Carless, 2011) but also Western contexts such as the US, England and Germany which increasingly focus on high-stakes assessment (Frick, 2013). With the growing emphasis on quantification and measurability in language education and standardized assessment around the world (Clarke \& Morgan, 2011; Frick, 2013), learners and TESOL practitioners may gradually focus more on learning for assessment, leading to the growing popularity of EPT. In fact, private tutoring has become a global phenomenon, both East and West, and "is emerging from the shadows and into the light” (Bray, 2009, p. 101). However, a current problem for policymaking in many places like Hong Kong is that government officials either do not have a clear picture of the situation regarding shadow education, or they are ignoring it. Therefore, as Bray and Lykins (2012) state, the first thing policymakers need to do is "to recognize the existence, nature, and implications of shadow education” (p. 71). TESOL practitioners may also need to consider the complex relationship between mainstream schools and out-of-class contexts like EPT regarding such issues as MOI, the roles of NESTs and NNESTs, and approaches to 
teaching and learning English.

An implication from the study regarding both policy and pedagogy is the legitimacy of regulating English teaching and learning in shadow education. EPT has become a huge business globally and is affecting student learning in both mainstream and out-of-class contexts, which may be in conflict with each other. For instance, while "learner autonomy is a paradigm shift in language learning pedagogy" (Miliander \& Trebbi, 2011, p. 4), EPT seems to be going in the opposite direction by adopting a teacher-dependent approach, at least in the Hong Kong context. Policymakers and TESOL practitioners may need to address a number of questions. Should alignment of teaching and learning in EPT with the mainstream education goals be part of the responsibility of the shadow education sector? Is EPT necessarily parasitic, or is it simply a product of the social dominance of performance culture, where utilitarianism has become exclusively the way of learning? Should teacher education worldwide, which has traditionally focused solely on mainstream education, start considering the impact of tutors on quality of learning both in-class and out-of-class? Policymakers and TESOL practitioners may need to start taking shadow education into account for curriculum planning and development.

Despite the vigorously growing popularity and expansion of EPT and its significant impact on the education systems around the world, EPT is still a “relatively underresearched area” in TESOL (Hamid et al., 2009, p. 303). The current study, while adding useful insights, only contributes to part of the research agenda in TESOL, and the complex relationship between mainstream and shadow education requires further investigation in a wider international context. This study can encourage studies on EPT as a part of the TESOL research agenda, in addition to enhancing the awareness of TESOL practitioners that the contextual realities of high-stakes examinations and the growing emphasis on performance goal should not 
overshadow the real aims of education in this globalized world, for which TESOL plays a significant part.

\section{ACKNOWLEDGMENTS}

My sincere thanks go to Prof. Agnes Lam, Prof. Mark Bray, Dr. Ora Kwo, Dr. Andy Gao, Mr. Jason Petsch, Prof. James Tollefson, Dr. Geoff Smith, Dr. Alan Hirvela, the TESOL Quarterly editors, particularly Dr. Ahmar Mahboob, and the anonymous reviewers for their constructive and valuable feedback on the earlier versions of this article. I would also like to thank the fourteen participants who shared their interesting and inspiring learning experiences with me.

\section{THE AUTHOR}

Kevin Yung teaches English for Academic and Specific Purposes at the Centre for Applied English Studies, The University of Hong Kong. He is currently researching in the area of English teaching and learning in shadow education at the Faculty of Education, The University of Hong Kong. His research interests include English learning motivation, autonomy, out-of-class language learning and learner narratives.

\section{REFERENCES}

Atkinson, D. (1999). TESOL and culture. TESOL Quarterly, 33(4), 625-654. doi: $10.2307 / 3587880$

Barkhuizen, G., Benson, P., \& Chik, A. (2014). Narrative inquiry in language teaching and learning research. New York, NY: Routledge.

Bell, J. S. (2011). Reporting and publishing narrative inquiry in TESOL: Challenges and rewards. TESOL Quarterly, 45(3), 575-584. doi: 10.5054/tq.2011.256792

Benson, P. \& Reinders, H. (2011). Introduction. In P. Benson \& H. Reinders (Eds.), 
Beyond the language classroom (pp. 1-6). London: Palgrave Macmillan.

Bray, M. (2009). Confronting the shadow education system: What government policies for what private tutoring? Paris: UNESCO International Institute for Educational Planning.

Bray, M., \& Kwo, O. (2014). Regulating private tutoring for public good: Policy options for supplementary education in Asia. Hong Kong: Comparative Education Research Centre and UNESCO.

Bray, M., \& Lykins, C. (2012). Shadow education: Private supplementary tutoring and its implications for policy makers in Asia. Hong Kong: Comparative Education Research Centre and Asian Development Bank.

Bray, M., Mazawi, A. E., \& Sultana, R. G. (Eds.). (2013). Private tutoring across the Mediterranean: Power dynamics and implications for learning and equity. Rotterdam: Sense Publishers.

Breen, L. J. (2007). The researcher 'in the middle’: Negotiating the insider/outsider dichotomy. The Australian Community Psychologist, 19(1), 163-174. Retrieved from http://www.groups.psychology.org.au/Assets/Files/Breen_19\%281\%29.pdf

Buchmann, C., Condron, D. J., \& Roscigno, V. J. (2010). Shadow education, American style: Test preparation, the SAT and college enrollment. Social Forces, 89(2), 435-461. doi: 10.1353/sof.2010.0105

Carless, D. (2011). From testing to productive student learning: Implementing formative assessment in confucian-heritage settings. New York, NY: Routledge.

Clandinin, D. J., \& Connelly, F. M. (2000). Narrative inquiry: Experience and story in qualitative research. San Francisco, CA: Jossey-Bass.

Clarke, M., \& Morgan, B. (2011). Education and social justice in neoliberal times: 
Historical and pedagogical perspectives from two postcolonial contexts. In M.

R. Hawkins (Ed.), Social justice language teacher education (pp. 63-85).

Bristol: Multilingual Matters.

Curriculum Development Council \& Hong Kong Examinations and Assessment Authority. (2007). English language education key learning area: English language (curriculum and assessment guide) Secondary 4-6. Hong Kong Special Administrative Region. Retrieved from http://www.edb.gov.hk/attachment/en/curriculum-development/kla/eng-edu/C urriculum\%20Document/EngLangCAGuide.pdf

Dörnyei, Z., \& Ushioda, E. (2011). Teaching and researching motivation (2nd ed.). Harlow: Longman.

Dawson, W. (2010). Private tutoring and mass schooling in East Asia: Reflections of inequality in Japan, South Korea, and Cambodia. Asia Pacific Education Review, 11(1), 14-24. doi: 10.1007/s12564-009-9058-4

Education Bureau. (2009). Education Bureau Circular No. 6/2009: Fine-tuning the medium of instruction for secondary schools. Hong Kong Special Administrative Region. Retrieved from http://www.edb.gov.hk/attachment/en/edu-system/primary-secondary/applicab le-to-secondary/moi/support-and-resources-for-moi-policy/lsplmfs-sch/d-sch/o w/sp/edbc09006e.pdf.

Forsey, M. (2013). But did it Help you get to university? A qualitative study of supplementary education in Western Australia. In J. Aurini, S. Davies \& J. Dierkes (Eds.), Out of the shadows: The global intensification of supplementary education (pp. 171-189). Bingley: Emerald Group Publishing Limited.

Frick, B. (2013). Fostering student creativity in the era of high-stakes testing. In J. 
Hattie \& E. M. Anderman (Eds.), International guide to student achievement (pp. 231-233). New York, NY: Routledge.

Gao, X. (2008). You had to work hard 'cause you didn't know whether you were going to wear shoes or straw sandals! Journal of Language, Identity \& Education, 7(3-4), 169-187. doi: 10.1080/15348450802237798

Hamid, M. O., Sussex, R., \& Khan, A. (2009). Private Tutoring in English for secondary school students in Bangladesh. TESOL Quarterly, 43(2), 281-308. doi: 10.1002/j.1545-7249.2009.tb00168.x

Holliday, A. (2010). Analysing qualitative data. In B. Paltridge \& A. Phakiti (Eds.), Continuum companion to research methods in Applied Linguistics (pp. 98-110). London: Continuum.

Kwok, P. (2004). Examination-oriented knowledge and value transformation in East Asian cram schools. Asia Pacific Education Review, 5(1), 64-75. doi:10.1007/bf03026280

Lee, B. (2010). The pre-university English-educational background of college freshmen in a foreign language program: A tale of diverse private education and English proficiency. Asia Pacific Education Review, 11(1), 69-82. doi: 10.1007/s12564-010-9079-z

Ma, L. P. F. (2012). Advantages and disadvantages of native- and nonnative-Englishspeaking teachers: Student perceptions in Hong Kong. TESOL Quarterly, 46(2), 280-305. doi: 10.1002/tesq.21

Mahboob, A. (2010). The NNEST lens. In A. Mahboob (Ed.), The NNEST lens: Non native English speakers in TESOL (pp. 1-17). Newcastle: Cambridge Scholar Publishing.

Miliander, J., \& Trebbi, T. (2011). Introduction. In J. Miliander \& T. Trebbi (Eds.), Educational policies and language learner autonomy in schools: A new 
direction in language education? (pp. 2-5). Dublin: Authentik.

Nunan, D. (2003). The impact of English as a global language on educational policies and practices in the Asia-Pacific region. TESOL Quarterly, 37(4), 589-613. doi: $10.2307 / 3588214$

Savin-Baden, M., Gourlay, L., \& Tombs, C. (2010). Researching in immersive spaces. In M. Savin-Baden \& C. H. Major (Eds.), New approaches to qualitative research: Wisdom and uncertainty (pp. 162-171). London: Routledge.

Watkins, D. A. (2009). Motivation and competition in Hong Kong secondary schools: The students' perspective. In C. K. K. Chan \& N. Rao (Eds.), Revisiting the Chinese Learner: Changing contexts, changing education (pp. 71-88). Hong Kong: Comparative Education Research Centre.

Wulf, D. (2010). A humor competence curriculum. TESOL Quarterly, 44(1), 155-169. doi: $10.5054 /$ tq.2010.215250

Yang, J. S., \& Kim, T. Y. (2011). Sociocultural analysis of second language learner beliefs: A qualitative case study of two study-abroad ESL learners. System, 39(3), 325-334. doi: 10.1016/j.system.2011.07.005

Zhan, S., Bray, M., Wang, D., Lykins, C., \& Kwo, O. (2013). The effectiveness of private tutoring: Students’ perceptions in comparison with mainstream schooling in Hong Kong. Asia Pacific Education Review, 14(4), 495-509. doi: 10.1007/s12564-013-9276-7

Zuengler, J., \& Miller, E. R. (2006). Cognitive and sociocultural perspectives: Two parallel SLA worlds? TESOL Quarterly, 40(1), 35-58. doi: 10.2307/40264510 
If you are willing to be contacted, please provide the following basic information:

Name:

Room number:

Email:

Contact number:

Signature:

Date:

1. Had you ever been a student in Hong Kong before you entered university?

$\square$ Yes (please go to Question 2) $\quad \square$ No (end of questionnaire)

2. Your (best) result in HKCEE English Language:

A/level 5*

$\square$ B/level 5

C C/level 4

D D/level 3

口 E/level 2

$\square$ F/level 1

$\square \mathrm{U}$

$\square$ No experience in taking HKCEE

3. Your (best) result in HKALE Use of English:
$\square \mathrm{A}$
$\square \mathrm{B}$
$\square \mathrm{C} \quad \square \mathrm{D}$
$\square \mathrm{E}$
$\square \mathrm{F}$
$\square \mathrm{U}$

$\square$ No experience in taking HKALE

4. Have you ever participated in any type of English tutoring?

$\square$ Yes (please go to Question 5) $\quad \square$ No (end of questionnaire)

5. Which of the following type(s) of English tutoring have you participated in?

(you may choose more than one answer)

$\square$ one-to-one private tutoring

$\square$ small group private tutoring (2 to 7 students in a group)

$\square$ large group tutoring in small-scale tutorial centre (specify class size:

$\square$ mass tutoring by star tutor in large-scale tutorial centre

(specify class size: )

$\square$ others (please specify:

6. During which time period(s) did you participate in English tutoring?

(you may choose more than one answer)

$\square$ before primary school

P Primary 1 to 3

Primary 4 to 6

Secondary 1 to 3

Secondary 4 to 5

Secondary 6 to 7

$\square$ after Secondary 7

- END OF QUESTIONNAIRE - 


\section{APPENDIX B}

\section{Interview probes}

\section{Part 1 - General background}

1. According to your answers in the questionnaire, you participated in one-to-one private tutoring/small group private tutoring/large group tutoring in small-scale tutorial centre/mass tutoring by star tutor in large-scale tutorial centre/(others), right?

2. When did you start each period of participation in tutoring and when did you end, if you did? I am interested in your experience from the very first occasion to the most recent one.

\section{Part 2 - Questions for each period of participation in tutoring}

Specific background

3. How often did you attend a lesson? How long was it? How much did you spend on English tutoring in a month? (In tutorial school, did you choose live-teaching or video-teaching? Why?)

Reasons, beliefs and attitudes

4. What were your beliefs in learning English at that time? What was your goal at that time? How was English important to you?

5. Why did you attend English tutorial lessons?

6. What do you think about this form of English tutoring? What were the pros and cons of this form of tutoring to you?

7. What was your school English teacher's attitude about your attending this type of English tutoring at that time, if he/she knew about it?

8. What was your parents' attitude about your attending English tutoring?

Teaching and learning strategies and motivation

9. How did you choose / were you affected by others in choosing the tutor / this type of tutoring?

10. What learning strategies and styles did you use when you were tutored? What do you think about them?

11. Why did you keep attending the tutor's lessons? What strategies did the tutor use in teaching English which you think were effective? How did he/she motivate you in learning?

12. Why did you quit tutoring/the tutor's lesson? Why did you change to another tutor if you did? Why did you change to another form of tutoring if you did? 


\section{Learning outcomes}

13. How did tutoring supplement your English learning at school?

14. What did you 'want' to get from tutoring? What did you really 'need' to get from tutoring? To what extent did tutoring meet your expectations in terms of 'needs' and 'wants'?

\section{Part 3 - Overall comparisons}

15. Which instance of tutoring was the best for you in learning English in terms of your learning outcomes, motivation and strategies? Why?

16. Which instance of tutoring was the worst for you in learning English in terms of your learning outcomes, motivation and strategies? Why?

17. I suppose you are no longer attending tutorial lessons, so what is your current perception on learning English through tutoring? Do you think young people should go? What do you think about the way English should be learned?

18. What else can you think of which may help me to understand your learning in tutoring better? 